\title{
Oncology
}

\section{Oncology Update for the Millennium}

In 1992, I was asked by Dr. Thomas Karger to assume responsibility for editing the journal Oncology. The task added to my duties considerably as Director of the University of Wisconsin Cancer Center, but I accepted the opportunity. Eight years later, I would like to summarize where we are and where I would like to see the journal heading in the next five years. Before doing so I want to thank all those who have submitted papers for review as well as the editorial board members and others for contributing manuscripts and spending their time reviewing the more than 220 papers submitted annually. I have more than 750 names of reviewers in my database used over the years. I also want to thank the editorial staff in Basel, Switzerland, for their hard work in managing the load of papers and setting up the publication.

First, I would like to provide the readers with some relevant information. Since 1995, we have seen a steady increase in manuscript submissions and now average over 20 papers per month submitted from more than 30 countries. The acceptance rate has gone down to 33\% from $53 \%$ in 1995 . This is due to higher standards for acceptance and an attempt on my part to encourage reports of larger clinical trials and rejecting the smaller, less organized ones. In addition, those papers that are not patientoriented I am likely to refer to other, more basic journals.

The review process is down to about 7 weeks and average time from acceptance to publication is around 4 months thanks to the state-of-the-art technology. Due to the success of Oncology, we were able to increase the frequency of the journal by adding two issues per year. Beginning in 1999, we started to publish 2 volumes each with 4 issues, totaling 8 issues yearly.

\section{KARGER}

๑) 2000 S. Karger AG, Basel

Fax +4161306 1234

E-Mail karger@karger.ch www. karger.com

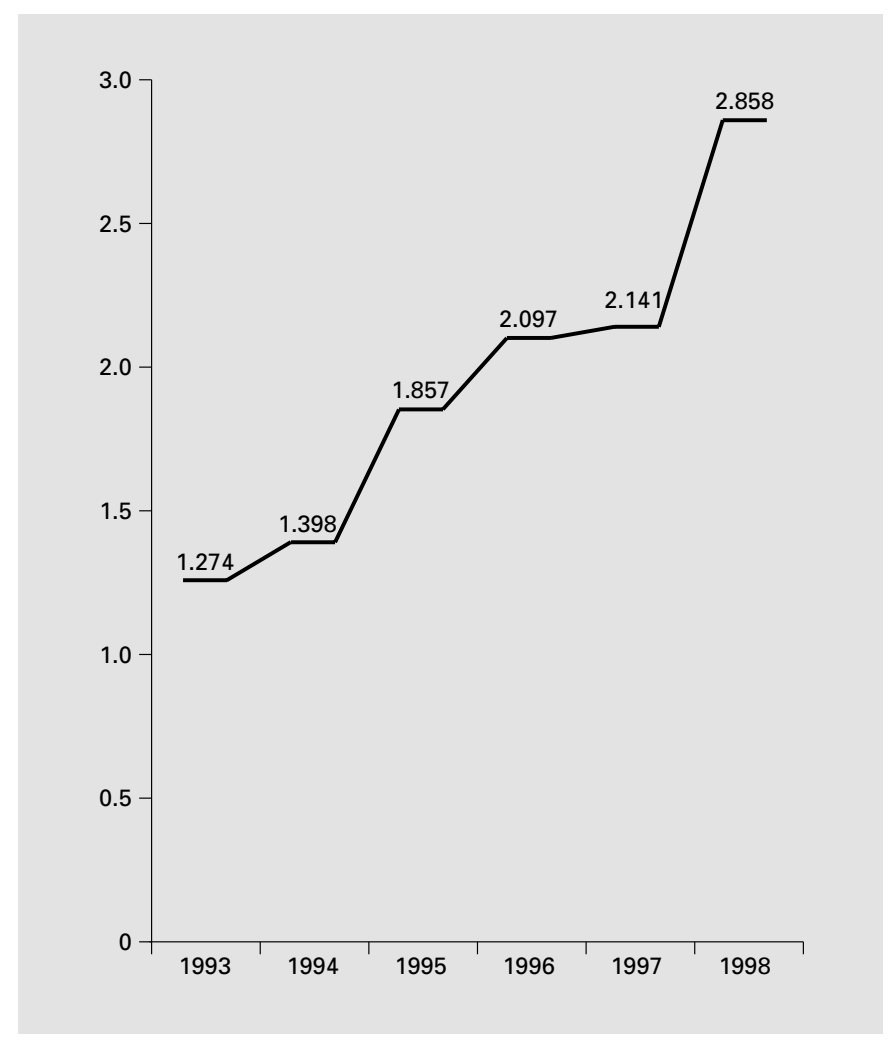

Fig. 1. 1993-1998 Impact Factor Ranking for Oncology.

In addition to submitted papers, we also instituted a Reviews section managed by Professor R. Herrmann of Basel on a variety of topics. Another component of our journal has been to publish proceedings of the important meetings as supplements. These supplements are made 
available to specific groups for their use, usually pharmaceutical companies. We also encourage letters, short case reports and regularly publish book reviews. Another change has been the cover which now features a figure or graph from an article in the respective issue.

All of this has led to an improvement in Oncology's impact rating to rank 21 out of over 100 publications, internationally. That rating is a measure of the utility and referencing by other papers. This is a remarkable growth in impact rating we should all be proud of (fig. 1). It means that of the hundreds of cancer journals, ours rates in the top 25 .

\section{Where Do I See the Journal Moving towards in the Next Century?}

- First, I want to encourage papers that are focussed on human cancer issues. This means that I want to emphasize those studies that deal with human cancers or patients. Those papers submitted that are strictly based on animal studies or cell culture where the connection to the human cancer problem is not clear, I will reject or refer to other journals. Not all clinical research is acceptable. There are papers that are obviously stretching the limits of the data by being too small a series or not controlled to justify the conclusions. I would encourage these authors to ask their statistical colleagues for help. I like to see papers that look at laboratory correlates of lab studies of risk, prognosis or outcomes. However, too many papers still employ lab observations in too small a series to make reasonable assumptions.

- I would like to continually update the use of the most modern informatics systems for all phases of the journal. Oncology is already available on the Internet for viewing. Visit the journal homepage at www.karger. com/journals/ocl.

- I foresee working closely together with our Editorial Board members to keep the journal a forerunner in its field.

- Finally, I want to invite feedback from all the readers of Oncology. Your input is valuable to us. Please let me know what we can do to make this a better Oncology.

Paul P. Carbone, Madison, Wisc. 